\begin{tabular}{c|c|c}
\hline \hline $\begin{array}{c}\text { Vol. 34(4):395-401 } \\
\text { http://dx.doi.org/10.4217/OPR.2012.34.4.395 }\end{array}$ & Ocean and Polar Research & December 2012 \\
\hline \hline
\end{tabular}

Article

\title{
Evidences of Intermittent Wind-Induced Flow in the Yellow Sea obtained from AVHRR SST Data
}

\author{
Young Ho Seung*, Jong-Hyuk Yoon, and Eun-Pyo Lim \\ Department of Oceanography, College of Natural Sciences, Inha University \\ Incheon 402-751, Korea
}

\begin{abstract}
Ten-year AVHRR sea surface temperature data obtained in the Yellow Sea are put into EOF analyses. Temperature variation is predominated by the first mode which is associated with the seasonal fluctuation of temperature with annual range decreasing with the bottom depth. Since such a strong annual signal may mask the upwind or downwind flows occurring intermittently during the winter, only the data obtained during this season are put into EOF analyses. Every winter shows similar results. The first mode, explaining more than $90 \%$ of total variance, appears to be a part of the seasonal variation of temperature mentioned above. In the second mode, the time coefficient is well correlated with northerly winds to which the responses of the trough and shallow coastal areas are opposite to each other. A simple theoretical consideration suggests the following physical explanation: The northerly wind stress anomaly creates an upwind (downwind) flow over the trough (coastal) areas, which then induces a temperature increase (decrease) by advection of heat, and vice versa for the southerly wind stress anomaly. Hence, this paper provides further evidence of the intermittent upwind or downwind flows occurring in the Yellow Sea every winter.
\end{abstract}

Key words : Yellow Sea, upwind flow, AVBHRR SST, EOF analysis

\section{Introduction}

The Yellow Sea is a semi-enclosed shallow basin with east-west and north-south dimensions of approximately $700 \mathrm{~km}$ and $1000 \mathrm{~km}$, respectively. Average bottom depth is about $44 \mathrm{~m}$ with about a $60-100 \mathrm{~m}$ trough running in the north-south direction along the axis of the basin (Fig. 1). The tidal current is much stronger than mean current such that observation of the latter is generally very difficult. A strong northerly monsoonal wind prevails in the winter bringing cold and dry continental air over the Yellow Sea, resulting in intense surface cooling and corresponding vertical mixing. In summer, the surface water is heated from above by solar radiation. The absorbed heat cannot penetrate deeply enough, resulting in a strong thermocline which separates the cold water formed during the previous winter from the warm surface water. The cold water mass

\footnotetext{
*Corresponding author. E-mail : seung@inha.ac.kr
}

below the thermocline is usually called the Yellow Sea Bottom Cold Water (Lie 1984).

South of the Yellow Sea, a warm current known as the Cheju Warm Current turns around Cheju Island toward the East Sea. This current forms the western part of the Tsushima Warm Current that originates ultimately from the Kuroshio, the western boundary current of the north Pacific subtropical gyre. The Cheju Warm Current is believed to supply heat and salt to the Yellow Sea but the detailed process is not known. Horizontal distributions of temperature and salinity in winter often show a tongueshaped northward intrusion of warm and saline water into the Yellow Sea. Correspondingly, it has been believed that there is a northward current flowing into the Yellow Sea from the East China Sea, called the Yellow Sea Warm Current (Uda 1934). A question arises whether the Yellow Sea Warm Current is a persistent mean flow or an intermittent flow. This problem is addressed by Lie (1984, 1985) and Lie et al. (2001). They conclude that the 


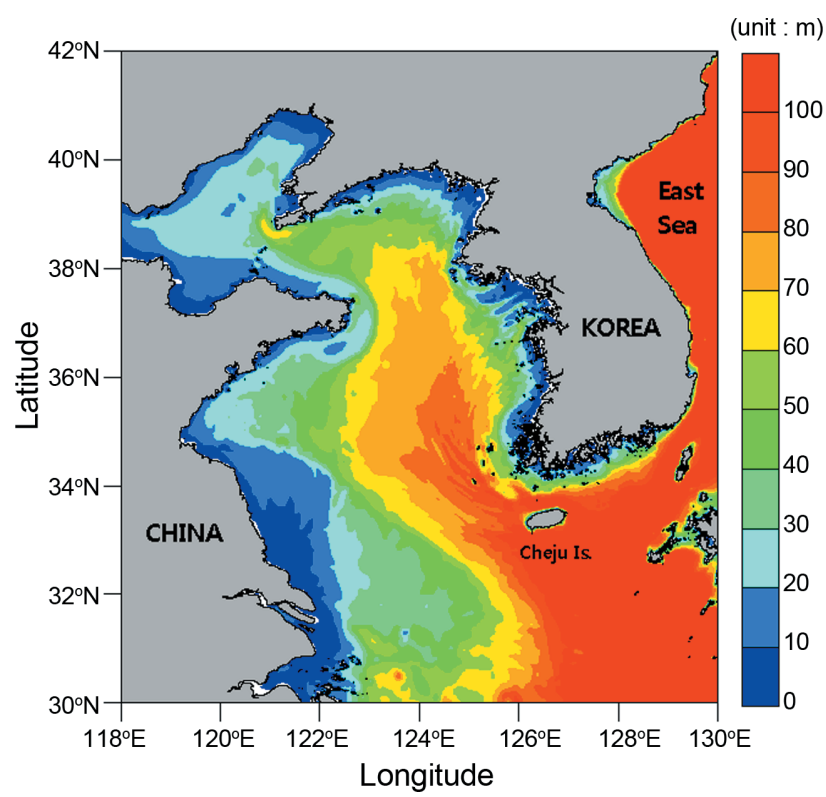

Fig. 1. Bathymetric chart of the Yellow Sea

Yellow Sea Warm Current is a wintertime intermittent flow of the Cheju Warm Current probably associated with wind events. In fact, Hsueh (1988) provides observational evidence of such flow. Currents are intermittently generated by strong wind, in the same and opposite directions over, respectively, shallow coastal and deep trough areas. This fact is further supported by numerical models (Naimie et al. 2001; Moon et al. 2009). Such downwind and upwind flows can physically be explained as follows. The wind stress is felt strongly (weakly) over a shallow (deep) region. If the net total transport along the basin vanishes, the downwind flow should occur in shallow regions and the upwind flow, in deep regions (Csanady 1982; Park 1986). It should be mentioned, however, that the Cheju Warm Current water can also move westward across the trough, on which some mechanisms are proposed (Huang et al. 2005; Lie et al. 2009; Lin and Yang 2011). The observational evidence of the intermittent upwind or downwind flow provided by Hsueh (1988) is only for a particular winter. This paper provides further observational evidence that such wintertime intermittent upwind or downwind flows occur every winter, based on ten-year AVHRR sea surface temperature data.

\section{Data analyses}

The data used in this paper are those of AVHRR sea surface temperature (SST) provided by NOAA and ECMWF wind stress. These data, covering the period from January

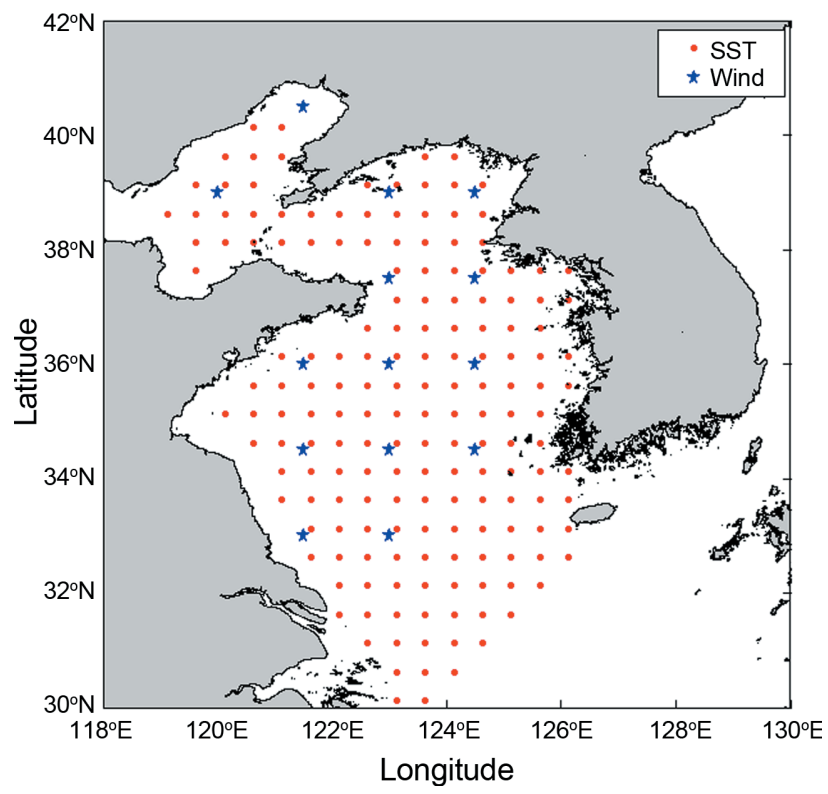

Fig. 2. Observational points of SST and wind

2000 to December 2009, are all converted to daily ones. Spatial resolutions of the AVHRR SST and ECMWF wind stress are, respectively, $0.5^{\circ}$ by $0.5^{\circ}$ and $1.5^{\circ}$ by $1.5^{\circ}$ in latitude and longitude (Fig. 2). The ten-year SST data are put into EOF analyses. The first and second modes explain, respectively, 98.00 and $0.66 \%$ of the total variance. The time coefficient of the first mode indicates that the latter is associated with the seasonal variation of temperature, largest in summer and smallest in winter (Fig. 3). The eigenvector of the first mode shows a spatial distribution pattern of magnitude decreasing with the bottom depth, i.e., increasing from south to north or from trough to coastal areas (Fig. 3). Physically, the first mode indicates the seasonal variation of temperature with annual range decreasing with the bottom depth. The eigenvector of the second mode shows an opposite distribution to that of the first mode. The corresponding time coefficient shows a semi-annual fluctuation. The second mode contributes very little to total variance and is not considered to be significant physically (Fig. 4).

The upwind or downwind flows occurring intermittently, mostly in winter, may be largely masked by the strong annual signal shown above (Fig. 3). They may be more easily detected by analyzing the SST data only obtained during the winter season, e.g., during the period from November to April of the next year. In order to relate the SST with the northern component of wind stress, the latter data are manipulated as follows. First, they are areaaveraged over the whole Yellow Sea because only a large- 

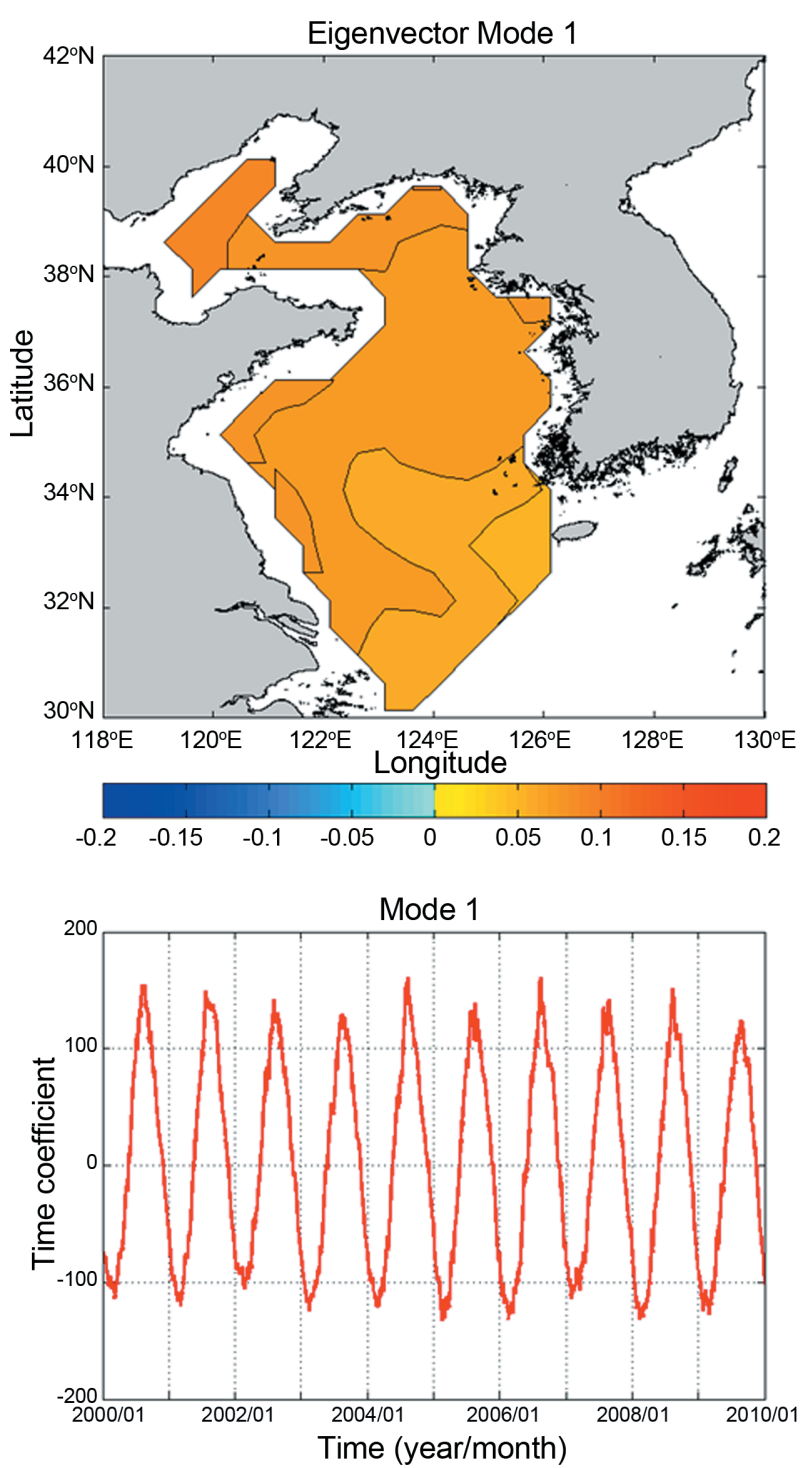

Fig. 3. Eigenvector and time coefficient of the first EOF mode for ten-year SST data

scale wind force may effectively drive the water motion in the Yellow Sea basin. Next, they are time-integrated from November and then a linear trend is subtracted from them. Note that such a process of time-integration and detrending is equivalent to that of time-integration after time-average is removed. For later convenience, the resulting manipulated values are referred to as "cumulative wind stress anomalies" where the anomaly means here the deviation from time-average. The reason why the "cumulative wind stress anomalies" are considered is because the latter is related with the SST change, as will be shown in the next section.

Nine pieces of the SST dataset are put into the EOF analysis and the corresponding nine results demonstrate
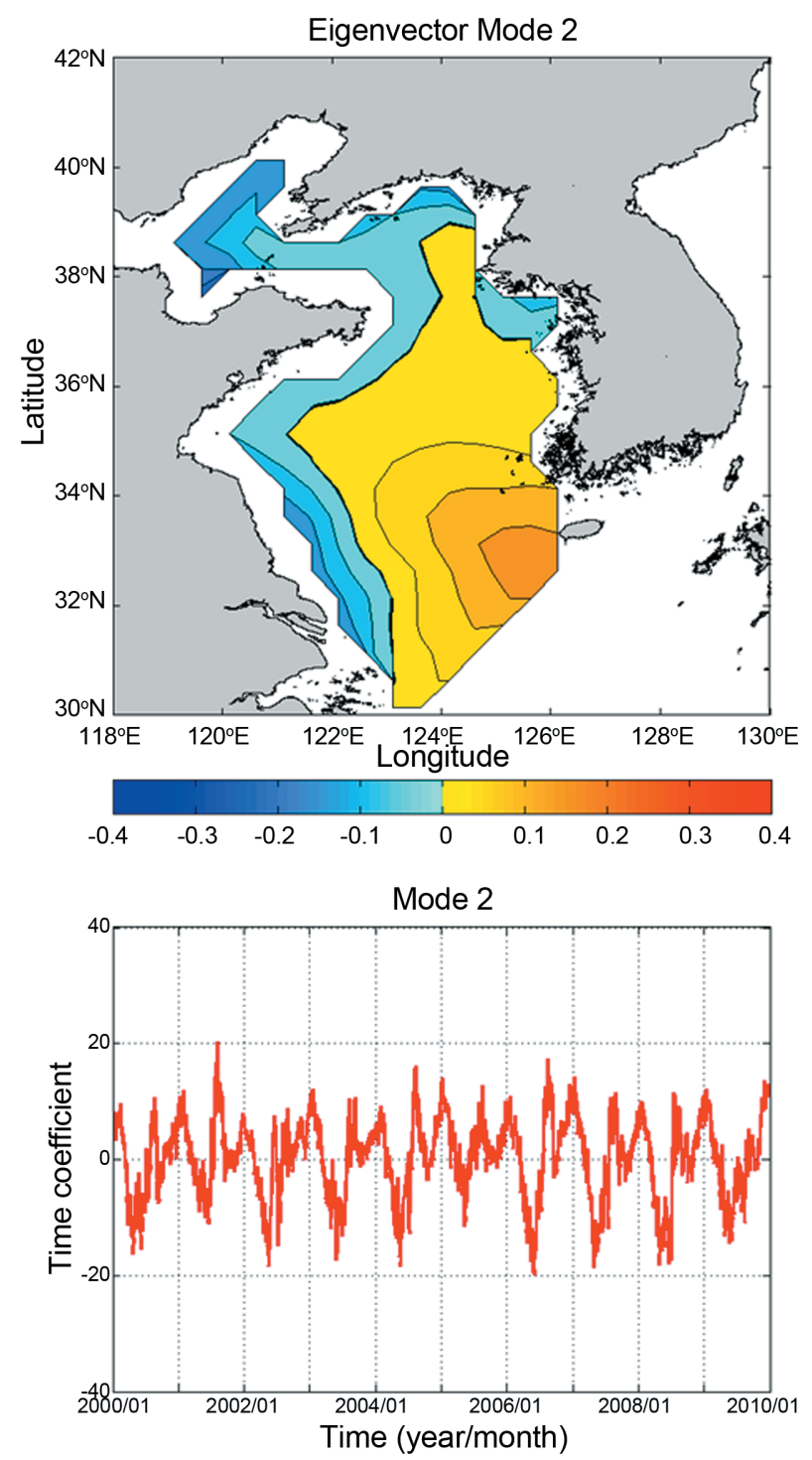

Fig. 4. Same as Fig. 3 except for the second mode

similar patterns to one another. As an example, the result for November 2003-April 2004 is described as follows. The first and second modes explain, respectively, 95.3 and $2.1 \%$ of the total variance. The eigenvector of the first mode shows nearly the same distribution pattern of magnitude as that of the seasonal variation of temperature, and the corresponding time coefficient shows a monotonic decrease and increase around the winter minimum (Fig. 5 ), indicating that the first mode corresponds to a part of the seasonal variation of temperature mentioned above. Although it may be somewhat related with wind, it certainly is not associated with the upwind or downwind event because the SST over the trough and coastal areas vary in the same phase. The eigenvector of the second mode has a distribution pattern of magnitude showing 

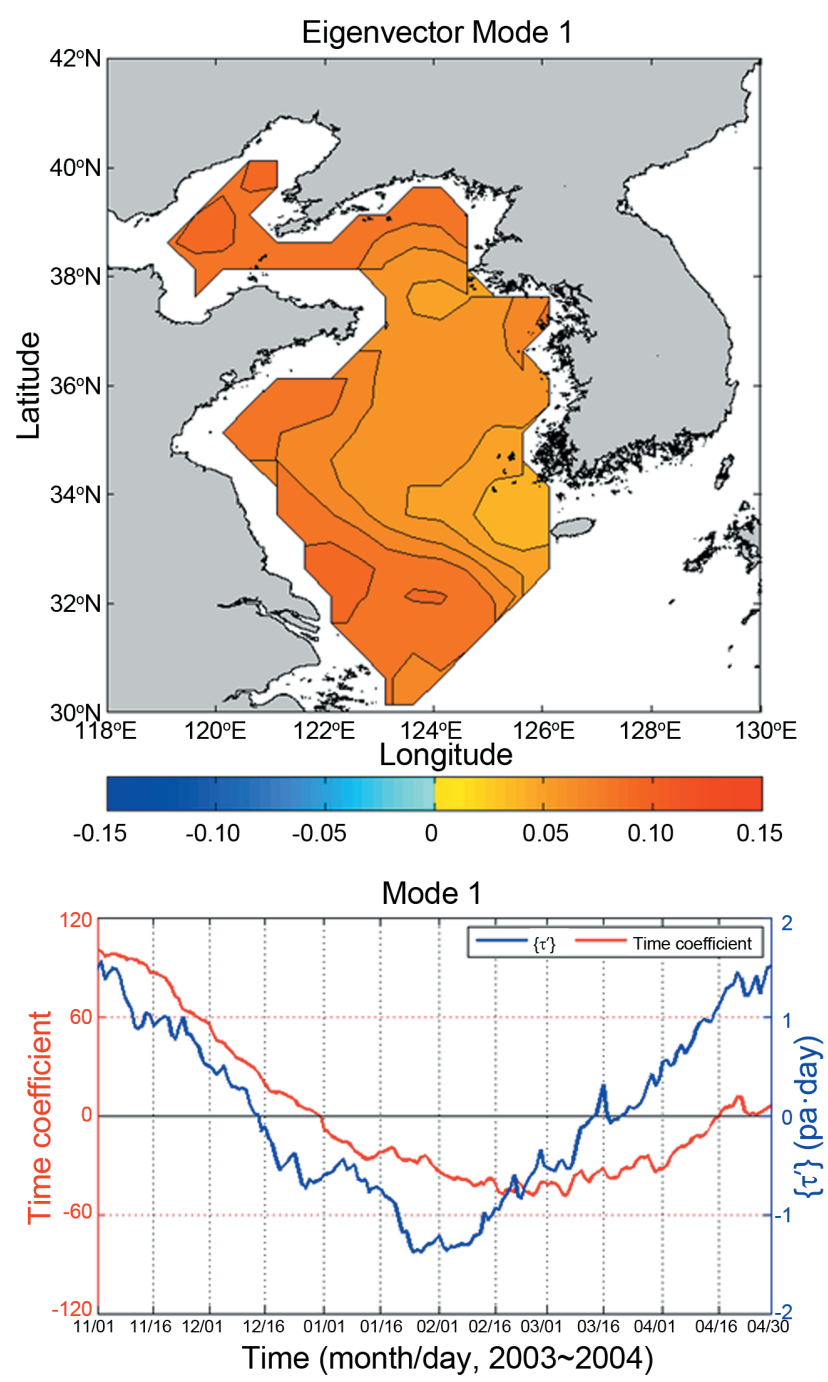

Fig. 5. Eigenvector and time coefficient of the first EOF mode for SST data obtained during the period from November 2003 to April 2004. For comparison, the "cumulative wind stress anomalies", $\{\tau$ ' $\}$, are plotted

positive values in the trough areas and negative values in the coastal areas (Fig. 6). The corresponding time coefficient appears to have a close relationship with wind, as described subsequently (Fig. 6). The time coefficient of the second mode and the "cumulative wind stress anomalies" are quite often negatively correlated with each other (Fig. 6). A similar feature is observed in every winter with a comparable magnitude of variances for both mode 1 and 2 (Table 1). In each winter, the second mode has an eigenvector with a distribution pattern similar to that in winter 2003-2004 (not shown). The corresponding time coefficient is quite often negatively correlated with the "cumulative wind stress anomalies" at a 5\% significance
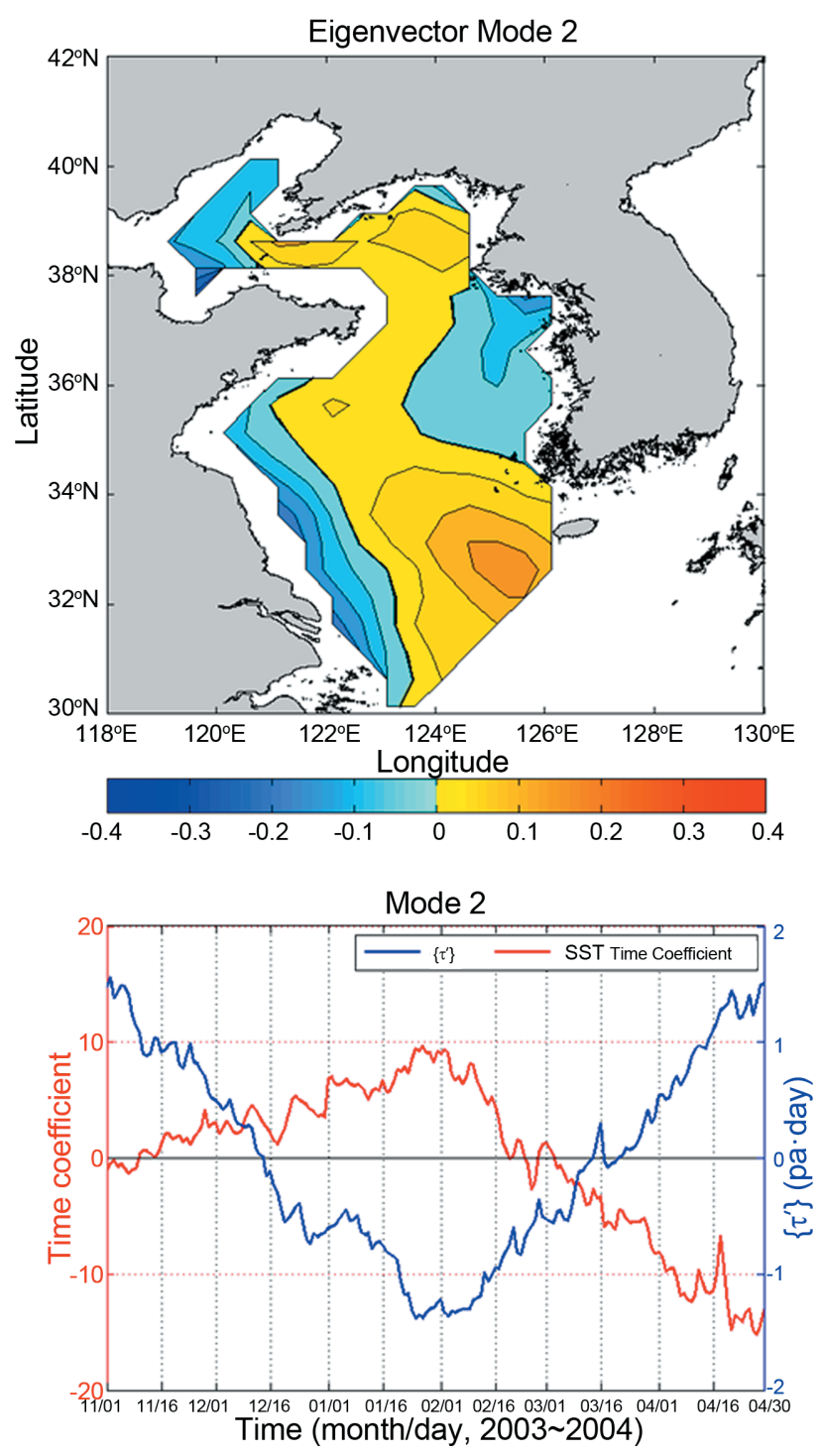

Fig. 6. Same as Fig. 5 except for the second mode

Table 1. Variances explained by EOF mode 1 and mode 2 for SST data obtained during each winter

(unit: \%)

\begin{tabular}{|c|c|c|}
\hline Year $\quad$ Mode & Mode 1 & Mode 2 \\
\hline $2000 \sim 2001$ & 96.9 & 1.5 \\
\hline 2001 2002 & 94.2 & 2.9 \\
\hline 2002 2003 & 95.5 & 2.3 \\
\hline 2003 2004 & 95.3 & 2.1 \\
\hline 2004 2005 & 97.1 & 1.2 \\
\hline $2005 \sim 2006$ & 95.8 & 2.3 \\
\hline $2006 \sim 2007$ & 94.6 & 3.1 \\
\hline 2007 2008 & 95.4 & 2.5 \\
\hline 2008 2009 & 95.1 & 2.5 \\
\hline
\end{tabular}




\begin{tabular}{|c|c|c|c|c|c|c|}
\hline Year & 11 & 12 & 1 & 2 & 3 & 4 \\
\hline $\begin{array}{l}2000 \\
\sim 2001\end{array}$ & & & & & & \\
\hline $\begin{array}{l}2001 \\
\sim 2002\end{array}$ & & & & & & \\
\hline $\begin{array}{l}2002 \\
\sim 2003\end{array}$ & & & & & & \\
\hline $\begin{array}{l}2003 \\
\sim 2004\end{array}$ & & & & & & \\
\hline $\begin{array}{l}2004 \\
\sim 2005\end{array}$ & & & & & & \\
\hline $\begin{array}{l}2005 \\
\sim 2006 \\
\end{array}$ & & & & & & \\
\hline $\begin{array}{l}2006 \\
\sim 2007\end{array}$ & & & & & & \\
\hline $\begin{array}{l}2007 \\
\sim 2008\end{array}$ & & & & & & \\
\hline $\begin{array}{l}2008 \\
\sim 2009\end{array}$ & & & & & & \\
\hline
\end{tabular}

Fig. 7. The months when the time coefficient of the second mode and the "cumulative wind stress anomalies" are negatively correlated with each other at a $5 \%$ significance level

level, as shown by the correlation coefficient obtained for every month (Fig. 7). The correlation is not strong in January and early February because the wind stress anomaly nearly vanishes and the SST does not change much during this time of the winter. The wind stress anomaly is generally negative in November-December, and positive in March-April. It will be shown in the next section that the wind stress anomaly creates upwind (downwind) flows over the trough (coastal) areas, and hence induces temperature change through advection of heat. One may argue that the variance explained by the second mode, being only a few percent, is too small to be significant. Practically, there is no way to prove such significance. However, it is stressed that similar second modes appear every winter.

\section{Theoretical consideration}

In the previous section, it was shown that temperature increases (decreases) with the northerly wind stress anomaly over the trough (coastal) areas. It remains to explain how they are related to each other. For this purpose, the problem is idealized as follows. Consider a long semienclosed basin with width $L$. The model basin is assumed

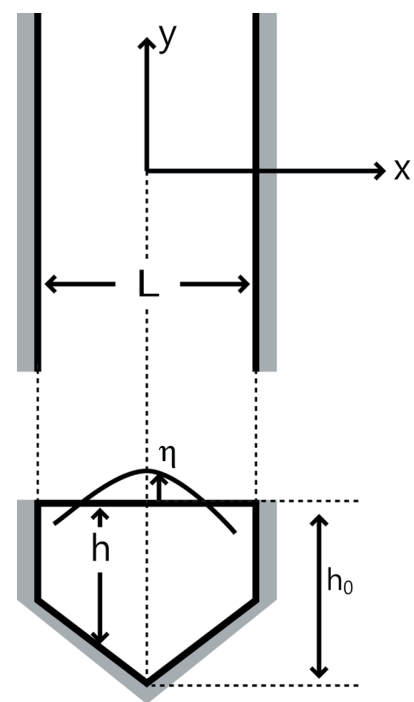

Fig. 8. Plan and side views of the model basin with free surface elevation, $\eta$

to be barotropic because the basin is vertically well mixed during the wintertime. Take a coordinate system with an $x$-axis in the cross-basin direction and a $y$-axis coinciding with the trough that lies along the center line of the basin (Fig. 8). Depth of the basin, $h$, is given by

$$
h(x)=h_{0}-s|x|, \text { for }-L / 2<x<L / 2
$$

where $h_{0}=h(0)$ is the maximum depth at the trough and $s$ is the bottom slope assumed to be a constant satisfying $2 h_{0} / L>s>0$. In the mean-state, it is assumed that

$$
\begin{aligned}
& \bar{u}=\bar{v}=0 \\
& g \bar{\eta}_{y}=\bar{\tau} / \rho h
\end{aligned}
$$

where $u$ and $v$ are $x$ - and $y$-components of current velocity, $g$ is gravity, $\eta$ is surface elevation measured from the mean surface level, subscript $y$ denotes differentiating with respect to $y, \tau$ is y-component of wind stress, $\rho$ is density of sea water, and over-bar denotes the mean-state. It can be said that in the mean-state, the pressure gradient force associated with the sea surface slope balances with the wind stress and sea water is motionless. In the meanstate, temperature, $T$, is assumed to be only a function of $y$ decreasing with $y$. The mean-state equilibrium is perturbed when wind stress becomes different from $\bar{\tau}$. Let $\tau=\bar{\tau}+\tau^{\prime}$ with prime denoting the anomaly from the mean-state. In the perturbed state, motions are assumed to be governed by linear dynamics and in the quasi-steady state with force balance being among wind stress, Coriolis' effect, pressure gradient and bottom friction: 


$$
\begin{aligned}
& f v^{\prime}-g \eta_{x}^{\prime}-\frac{\gamma u^{\prime}}{h}=0 \\
& -f u^{\prime}-g \eta_{y}^{\prime}+\frac{\tau^{\prime}}{\rho h}-\frac{\gamma v^{\prime}}{h}=0
\end{aligned}
$$

where $f$ is the Coriolis' parameter, $\gamma$ is the bottom friction coefficient and prime denotes the perturbation. The continuity equation is

$$
\left(u^{\prime} h\right)_{x}+\left(v^{\prime} h\right)_{y}=0
$$

From (6), define transport stream function, $\Psi$, such that

$$
\psi_{x}=v^{\prime} h, \psi_{y}=u^{\prime} h
$$

Boundary condition of $\Psi$ is

$$
\psi=0 \text {, at } x= \pm L / 2
$$

Cross-differentiating (4) and (5), and using (7) lead to

$$
\left(f \psi_{y}+\tau^{\prime}\right)\left(\frac{1}{h}\right)_{x}-\gamma\left[\left(\frac{\psi_{x}}{h^{2}}\right)_{x}+\left(\frac{\psi_{y}}{h^{2}}\right)_{y}\right]=0
$$

Assume that the variation in the $y$-direction is much smaller than that in the $x$-direction such that $\left(\Psi_{y} / h^{2}\right)_{y}$ can be neglected compared to $\left(\Psi_{x} / h^{2}\right)_{x}$ and that $f \Psi_{y}$ can be neglected compared to $\tau^{\prime}$ in (9). Integrating the resulting (9) two times with respect to $x$ and applying (8) lead to

$$
\begin{aligned}
\psi & =\frac{\tau^{\prime}}{\gamma}<h>\left[\frac{\int_{-L / 2}^{x} h d x}{<h>}-\frac{\int_{-L / 2}^{x} h^{2} d x}{<h^{2}>}\right] \\
& =\frac{\tau^{\prime}}{\gamma}<h>[\alpha(x)-\beta(x)]
\end{aligned}
$$

where $<>$ denotes the integration from $x=-L / 2$ to $x=L / 2$. It can be shown that $\alpha(-L / 2)=\beta(-L / 2)=0, \alpha(x)>\beta(x)$ for $-L / 2<x<0, \alpha(0)=\beta(0)=0.5, \beta(x)>\alpha(x)$ for $0<x$ $<L / 2$ and $\alpha(L / 2)=\beta(L / 2)=1.0$ (Fig. 9). For $\tau^{\prime}>0, \Psi$ increases from 0 at $x=-L / 2$, becomes maximum at $x=$ $-L / 4$, decreases toward $\Psi=0$ at $x=0$, further decreases becoming minimum at $x=L / 4$, and increases again toward $\Psi=0$ at $x=L / 2$ (Fig. 10). Correspondingly, $v^{\prime}\left(=\Psi_{x} / h\right)$ is in the negative $y$-direction over the trough areas, $|x|<L / 4$, and in the positive $y$-direction over the shallower areas, $L / 4<|x|<L / 2$ (Fig. 10). Hence, $v^{\prime}$ is negatively and positively correlated with the wind stress anomaly $\tau^{\prime}$ over, respectively, the trough and shallower areas. It can be said that

$$
\begin{aligned}
& v^{\prime}(t) \propto \tau^{\prime}(t) \text { for } L / 4<|x|<L / 2 \\
& v^{\prime}(t) \propto-\tau^{\prime}(t) \text { for }|x|<L / 4
\end{aligned}
$$

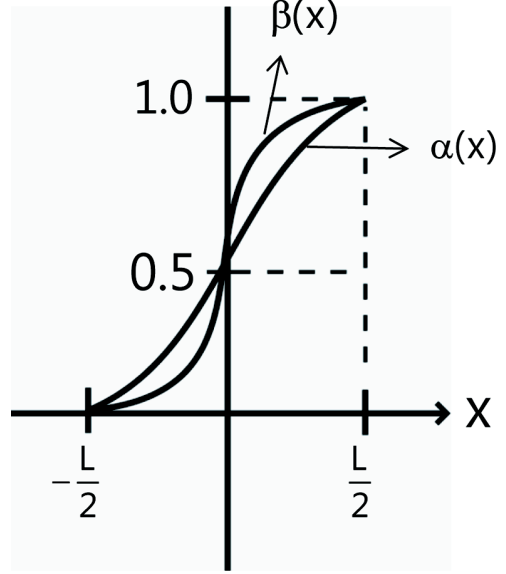

Fig. 9. $\alpha(x)$ and $\beta(x)$ as defined in (10). The bottom depth $h(x)$ is given in (1)

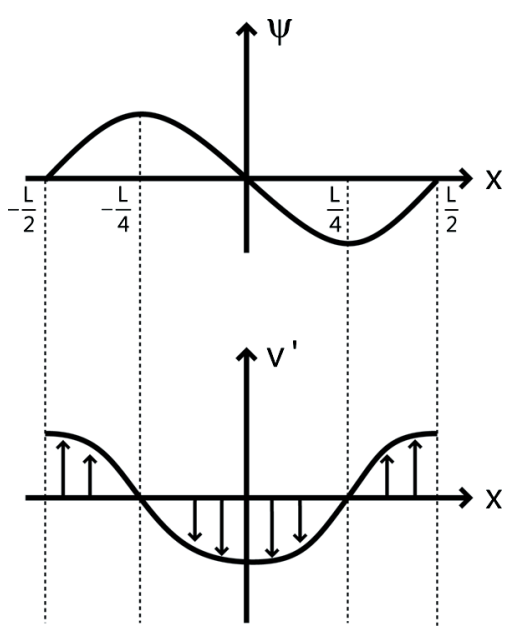

Fig. 10. Profiles of $\psi(x)$ and $v^{\prime}(x)$ across the basin estimated according to (10). Units are arbitrary

In the meantime, temperature, $T$, is also perturbed by the wind stress anomaly. If we consider only the advection of heat by current, neglecting surface cooling or heating, the perturbation of temperature is governed by

$$
T_{t}^{\prime}=-v^{\prime} \bar{T}_{y}
$$

where the subscript $t$ denotes the time-derivative and $\bar{T}_{y}$ is negative. Time-integrating (13) and using (11) and (12) lead to

$$
\begin{aligned}
& T^{\prime}(t) \propto-\bar{T}_{y} \int \tau^{\prime} d t \text { for } L / 4<|x|<L / 2 \\
& T^{\prime}(t) \propto \bar{T}_{y} \int \tau^{\prime} d t \text { for }|x|<L / 4
\end{aligned}
$$

where the time integration of $\tau^{\prime}$ is the "cumulative wind 
stress anomaly". Hence, according to (14) and (15), temperature over the shallow (trough) areas increases (decreases) with the "cumulative wind stress anomaly." Overall, upwind (downwind) flow is created over the trough (shallow) areas by northerly winds, as indicated by (12) ((11)), which then causes temperature increase (decrease) by advection of heat, as indicated by (15) ((14)).

\section{Concluding remarks}

In the Yellow Sea, it has been observed that currents are intermittently generated by strong wind, in the same and opposite directions over, respectively, shallow coastal and deep trough areas. To provide further evidence that such wintertime intermittent upwind or downwind flows occur every winter, ten-year AVHRR sea surface temperature data are put into EOF analyses. The SST variation is largely dominated by annual fluctuation, with amplitude decreasing with bottom depth, i.e., increasing from south to north or from trough to coastal areas. Since such a strong annual signal may mask the upwind or downwind flows occurring intermittently in winter, only the data obtained during the winter season, e.g., during the period from November to April of the next year, are put into EOF analyses. The results for nine winters show similar patterns to one another. The first mode explains more than $90 \%$ of the total variance. The eigenvector of the first mode demonstrates nearly the same distribution pattern of magnitude as that of the seasonal variation and the corresponding time coefficient shows a monotonic decrease and increase around the winter minimum, indicating that the first mode corresponds to a part of the seasonal variation of temperature. The second mode explains a few percent of total variance. The eigenvector of the second mode shows positive values in the trough areas and negative values in the coastal areas. The time coefficient of the second mode is quite often negatively correlated with the "cumulative wind stress anomalies." A simple theoretical consideration gives an explanation of the second mode: The northerly wind stress anomaly creates an upwind (downwind) flow over the trough (coastal) areas, which then induces a temperature increase (decrease) by advection of heat, and vice versa for the southerly wind stress anomaly. Although the second mode explains only a few percent of the total variance, the fact that it occurs every winter is quite significant. It can be said that this paper provides further evidence of the intermittent upwind or downwind flows occurring in the Yellow Sea every winter.

\section{Acknowledgements}

This study is supported by Inha University.

\section{References}

Csanady GT (1982) Circulation in the Coastal Ocean. D Reidel Publishing Company, London, 277 p

Huang D, Fan X, Xu D, Tong Y, Su J (2005) Westward shift of the Yellow Sea warm salty tongue. J Geophys Res Lett 32:L24613. doi:10.1029/2005GL024749

Hsueh Y (1988) Recent current observations in the Eastern yellow Sea. J Geophys Res 93(C6):6875-6884

Lie HJ (1984) A note on water masses and general circulation in the Yellow Sea (Hwanghae). J Oceanol Soc Korea 19:187-194

Lie HJ (1985) Wintertime temperature-salinity characteristics in the southeastern Hwanghae (Yellow Sea). J Oceanogr Soc Japan 41:291-298

Lie HJ, Cho CH, Lee JH, Lee S (2001) Does the Yellow Sea warm current really exist as a persistent mean flow? J Geophys Res 106:22199-22210

Lie HJ, Cho CH, Lee JH, Lee S (2009) Tongue-shaped frontal structure and warm water intrusion in the southern Yellow Sea in winter. J Geophys Res 114:C01003. doi:10.1029/2007.JC004683

Lin X, Yang J (2011) An asymmetric upwind flow, Yellow Sea Warm Current: 2. Arrested topographic waves in response to the northwesterly wind. J Geophys Res 116: C04027. doi:10.1029/2010JC006514

Moon JH, Hirose N, Yoon JH (2009) Comparison of wind and tidal contributions to seasonal circulation of the Yellow Sea. J Geophys Res 114:C08016. doi:10.1029/ 2009JC005314

Naimie CE, Blain CA, Lynch DR (2001) Seasonal mean circulation in the Yellow Sea - a model generated climatology. Cont Shelf Res 21:667-695

Park YH (1986) A simple theoretical model for the upwind flow in the southern Yellow Sea. J Oceanol Soc Korea 21:203-210

Uda M (1934) The result of simultaneous oceanographical investigations in the Japan Sea and its adjacent waters in May and June 1932. J Imperial Fish Exp Sta 5:138-190

Received Oct. 9, 2012

Revised Nov. 13, 2012

Accepted Nov. 17, 2012 